\title{
Ophthalmology: ozone therapy applied to dystrophic maculopathy
}

\author{
Giorgio Grechi
}

Oculist

\begin{abstract}
The macula, which is the noblest part of the retina, is a very small structure, containing the photoreceptors (rods and cones) responsible for visual acuity. Over the years, observations have confirmed that alterations that modify the optimal state of the eye also give rise to similar diseases in the brain: ischemias, structural circulatory alterations and neurodegeneration. As the body ages, oxidative alterations take place and they change the antioxidant systems that serves as a neurological and ocular defence. In industrialised nations, age-related macular degeneration is the leading cause of blindness in patients over 55 years of age. Initially, this creates drusen (or colloid cysts) in the macular area.
\end{abstract}

\section{Introduction}

The neurological parts of the eyes (retina and optic nerve) are closely related to the brain in embryogenesis, and are an extension of it. They share many common structural characteristics, from an anatomic-neurophysiological perspective: i) a cardio circulatory component; ii) metabolic regulation; iii) oxygenation; and iv) extracellular $\mathrm{pH}$ values.

The circulatory component presents the blood-brain barrier in the brain, as well as the blood-retinal barrier in the eye. Systemic arterial pressure is maintained within well-defined values, as is ocular pressure in the eye. The same is true of the metabolic and biochemical components.

When assessing diseases that affect the brain and the eye, ath-

Correspondence: Giorgio Grechi, Oxygen-Ozone Therapy Scientific Society, via Roma 69, 24020 Gorle (BG), Italy.

E-mail: info@ossigenoozono.it

Key words: Oxygen-ozone therapy; Ophthalmology; Dystrophic maculopathy.

Received for publication: 12 April 2017.

Accepted for publication: 3 May 2017.

(C) Copyright G. Grechi, 2017

Licensee PAGEPress, Italy

Ozone Therapy 2017; 2:6746

doi:10.4081/ozone.2017.6746

This article is distributed under the terms of the Creative Commons Attribution Noncommercial License (by-nc 4.0) which permits any noncommercial use, distribution, and reproduction in any medium, provided the original author(s) and source are credited. erosclerosis and individual ageing are important. The degeneration that occurs in the various components our bodies are made from can also be found in neurological structures. As predisposing causes, in addition to the two set out above, we should also add lifestyle (smoking and alcohol), the type of environment, diet (as with all metabolic disorders) and finally, genetic and hereditary factors.

For example, the macula, which is the noblest part of the retina, is a very small structure, approximately $500 \mu \mathrm{m}$ thick, which contains the photoreceptors (rods and cones) that are responsible for visual acuity. Over the years, as a result of the foregoing, observations made at many facilities have confirmed that alterations which have a deleterious effect on optimal eye state, also give rise to similar diseases in the brain: ischemias, structural alterations in the circulatory system and neurodegeneration. As the body ages, oxidative alterations occur that change the antioxidant systems that defend neurological and ocular components.

In industrialised nations, age-related macular degeneration (AMD) is the leading cause of blindness in patients over 55 years of age. Initially, this creates drusen (or colloid cysts) in the macular area.

The regression of drusen over time gives rise to atrophic macular tissue. As time goes on, the clinical picture worsens, and we can observe a retinal dystrophy with a generic thinning (dystrophy) that annuls the foveal curvature; this, however, almost exclusively involves the deep retinal layers, the pigmented epithelium and photoreceptive layers.

Such atrophy is called dry maculopathy, and should not be confused with wet maculopathy, which is characterised by a chorio-retinal neo vascularisation with lifting of the pigmented retina. Once the disease is triggered (in either of the two cases), within the span of a few years, the patient will experience a partial decline in visual acuity, of the type that worsens.

Such diseases, in general, result in a loss of central vision. For diagnosis, methods such as ocular fundus imaging, ocular fundus autofluoresence, microperimetry, and spectral domain optical coherence tomography (SD-OCT) are used.

\section{Case Report}

The multi-centred AREDS study (Italian acronym for agerelated eye diseases study) demonstrated that in patients with moderate to severe AMD, oral use of a combination of vitamin $\mathrm{C}$ (500 mg), vitamin E (400 IU), beta-carotene (15 mg) and zinc (80 $\mathrm{mg}$ ) led to a $25 \%$ reduction in the relative risk of developing advanced AMD in the other eye within 5 years. ${ }^{1}$

The absence of a specific therapy for AMD emerging to date, with its well-known degenerative characteristics, suggests an interesting hypothesis: that improving $\mathrm{O}_{2}$ transport to the macular area might slow the disease progression. 
For this reason, over the last two years, I decided to use $\mathrm{O}_{2}-\mathrm{O}_{3}$ therapy to treat dry maculopathy at a concentration of $30 \mu \mathrm{g} / \mathrm{mL}$ on the assumption that it had the safe property of improving the microcirculation. Twelve patients with dry AMD were subjected to $\mathrm{O}_{2}-\mathrm{O}_{3}$ therapy for a cycle of at least $12-14$ sessions (2 per week for the first 3 weeks and thereafter one session a week for at least another 6-8 weeks). At subsequent eye examinations, it was noted that in order to maintain the results obtained, it was necessary to assess visual acuity every 30 days and, if an initial decrease in visual acuity was observed, a monthly booster of $\mathrm{O}_{2}-\mathrm{O}_{3}$ therapy was added.

The mixture of $\mathrm{O}_{2}-\mathrm{O}_{3}$ was administered by autohaemoinfusions, composed of $150 \mathrm{cc}$ of the patient's blood with $150 \mathrm{cc}$ of $\mathrm{O}_{2-}$ $\mathrm{O}_{3}$ at a concentration of $30 \mu \mathrm{g} / \mathrm{mL}$. $^{2}$

An ozone delivery unit [model: Medical Ozone 95 CPS from Multiossigen Srl (Gorle, BG), Italy], and an autohaemotherapy kit (model: SANO3 specifically certified for use with blood and ozone) were used.

\section{Discussion}

After examining 15 patients aged between $65-85$ years, the results were very encouraging: most had a visual acuity that had either stabilised or not worsened over the previous two years, whilst visual acuity had improved in two patients.

\section{Conclusions}

OCT currently represents one of the most precise and advanced methods for diagnosing and controlling age-related macular pathologies; following $\mathrm{O}_{2}-\mathrm{O}_{3}$ therapy this technique disclosed no variations. ${ }^{3}$ For this reason, I believe that the action of this therapy on cells generates an increase in their oxygenation, and thus improves the metabolism of the remaining cells which are responsible for the visual acuity of the individual.

\section{References}

1. Buratto L. Mangiare per gli occhi. Occhio e nutrizione. Heidelberg: Springer Verlag; 2010.

2. Franzini M. Ossigeno Ozono Terapia che cos'è e cosa fa manuale della buona salute senza dolore. Gorle: SIOOT Società scientifica di ossigeno-terapia; 2010.

3. Lombroso B, Brancato R. Guida pratica all'interpretazione dell'OCT. Rome: Innovation-News-Communication; 2003. 